\title{
ТРАНСФОРМАЦИИ ИНФОРМАЦИОННЫХ ЖАНРОВ ЖУРНАЛИСТИКИ В ЭПОХУ ИНТЕРНЕТ-СМИ: КЛАССИФИКАЦИЯ, СТРУКТУРНЫЕ И СТИЛИСТИЧЕСКИЕ ОСОБЕННОСТИ
}

\author{
Ерицян Асмик Егишевна \\ Российско-Армянский Университет \\ Институт медиа, рекламы и кино \\ Аспирант 3-го курса
}

\begin{abstract}
Аннотация. В данном исследовании мы рассмотрели трансформации информационных жанров журналистики в эпоху информационных технологий и развития интернет-СМИ, а также выделили структурные, языковые и стилистические особенности современной новостной заметки.

Abstract. In this study, we investigate the transformation of information journalism genres in the age of information technology and development of online media and consider the structural, linguistic and stylistic features of a
\end{abstract} modern news article.

Ключевые слова: мультимедийная журналистика, интернет-СМИ, жанр, новость, заголовок, лид.

Keywords: multimedia journalism, online media, genre, news, headline, lead paragraph (lead).

Развитие современных цифровых платформ существенным образом повлияло на журналистику и на продукты журналистской деятельности - журналистские материалы. Этот процесс привел к потребности детального изучения структурных характеристик современных журналистских материалов (в нашем исследовании - материалов информационных жанров), а также пересмотра принципов их написания и жанровой классификации.

Ранее в газетной журналистике принято было выделять несколько информационных жанров, начиная от информационной заметки, заканчивая информационным репортажем. Однако мы, на основе мониторинга современных русскоязычных информационных агентств и интернет-изданий («Лента.Ру», ТАСС, РИА Новости, «Новая Газета», «Настоящее время», «Медуза»), а также новостных отделов сайтов авторитетных зарубежных медиа (BBC, Deutsche Welle, Euronews) пришли к выводу, что данный этап характеризуется слиянием традиционных жанров информационной журналистики в единый мультимедийный формат - с четко выраженными структурными и стилистическими особенностями, что дает нам право выделить данный формат подачи информационного материала в самостоятельный жанр - «новость».

Современная новость (или информационная заметка) - это именно тот жанр журналистики, в котором строго соблюдается принцип единства формы и содержания: форма отличается четкой композиционной структурой, стилистикой, которая диктует особый синтаксис и лексику, содержание подразумевает наличие свершившегося факта (какое-либо происшествие или событие).

Таким образом, в данном исследовании мы будем выделять «новость» как отдельный медиажанр, который перенял у информационных жанров традиционной газетной журналистики свое онтологическое свойство - ядром новости является событие, происшествие.

Новости являются движущей силой журналистики, ядром как традиционных, так и современных интернет-СМИ. Ведь онтологическая функция журналистики - предоставление свежей информации о происшествиях, событиях, инновациях и т.п. в различных сферах жизни. Более того, эта функция журналистики удовлетворяет одну из социальных потребностей человека - потребность в информации.

Но что же такое новость как категория? Что можно считать новостью? Эти вопросы вполне закономерны, когда речь идет о новости не только как о жанре, но и категории.

Колесниченко в своем учебном пособии «Практическая журналистика» пишет, что в журналистике существует два определения новостей. Согласно первому, которое приведено в источнике, новости - это информация, необходимая людям для принятия решения, которое будет касаться их дальнейшей жизни. Согласно второму, новость - это отклонение от естественного хода событий [1, с. 17].

«Первым случаем новостью будет, к примеру, принятие нового закона или ежегодное послание президента. Во втором - всевозможные чрезвычайные и курьезные происшествия. К этому случаю относится знаменитая поговорка: "Когда собака укусила человек, это не новость, а когда человек укусил собаку, это уже новость" $[1$, с. 17]».

Чтобы содержательная сторона новости не оставляла у читателей вопросов, журналисту следует дать ответы на 6 основных вопросов: Кто? Что? Где? Когда? Почему? Каким образом? В любой новости, даже если речь идет о короткой заметке или молнии, нужно обязательно дать ответы как минимум на вопросы: Что? Где? Когда? Это так называемое правило $3 \mathrm{~W}$ (на английском языке все эти вопросы начинаются с буквы «W»).

Принцип перевернутой пирамиды, применяющийся традиционной газетной журналистике, также актуален и для новостей в интернет-СМИ. Согласно данному принципу, журналист имеет право нарушить 
хронологию события и вынести в начало своего материала (лид, заголовок) самый важный и интересный факт. «Поэтому «перевернутую пирамиду» еще называют антиисторией в противоположность истории как повествованию, нарративу» [1, с.19].

Перейдем от содержательных особенностей новостей к разбору их структурных и языковых характеристик - от содержания к форме.

Структурно современная новость состоит из заголовка и лида, которые мы будем называть ядром новости, так как в них раскрывается вся информация о происшествии, деталей и бэкграунда.

В новостях интернет-СМИ принято использовать глагольные заголовки, в которых уже содержится ответ на вопросы: Что? Где? Когда? После заголовка идет развернутый лид, который не должен сливаться с заголовком. В лиде предоставляются уже подробности и некоторые детали события. Например, кто заявил о нем, где конкретно оно произошло и прочее; в нем можно найти ответ на вопрос «Откуда нам стало это известно?», так как обычно в лиде содержится ссылка на источник.

Заголовок и лид по праву считаются ядром новости, так как именно в них содержится основная информация о происшествии и именно в них содержится ответы на основные вопросы, интересующие читателей. Как в российских, так и в зарубежных СМИ это правило практически стало догмой для структуры новостного текста. Именно глагольные заголовки и развернутый лид являются самым распространенным и наглядным результатом трансформации традиционных информационных жанров в эпоху современных технологий.

Детали раскрывают обстоятельства и подробности вокруг события, о котором говорилось в ядре. В краткой новости детали не используются обычно потому, что они еще не известны или уточняются. Детали обязательно используются в расширенной новости; они должны быть логически связаны с ядром новости.

Бэкграунд - это дополнительная информация, благодаря которой читатель может глубже понять смысл новости, узнать о событиях, предшествующих ей, статистических данных, а также об аналогичных событиях, произошедших ранее.

Если ядро, как правило, располагается в начале новости, то место деталей и бэкграунда может варьироваться в зависимости от предпочтений редактора или журналиста. Чаще всего, бэкграунд помещают в конец материала или в некоторых случаях сразу после заголовка и лида. Разберем новостной материала из СМИ, в котором выделим его структурные особенности.

«В Якутии организуют автомобильный тур на полюс холода для иностранных гостей [2]

ЯКУТСК, 14 марта. /ТАСС/. Власти Якутии организуют автомобильный тур протяженностью свыше 2 тыс. км до полюса холода в Оймяконском районе Якутии для иностранных туристов. Туристьл познакомятся с культурой и бытом оленеводов, поучаствуют в подледной рыбалке и искупаются в незамерзающих источниках на полюсе холода, сообщили в туристско-информационном ичентре "Якутия" ядро новости: заголовок, лид, ссылка на источник.

"Событийный тур представляет собой автомобильное путешествие в составе ралли-рейда, туристы за несколько дней преодолевают около 2 тыс. км (Якутск - Оймякон - Якутск). Они пройдут якутский обряд очищения, познакомятся с культурой и бытом северных народов, встретятся с якутским повелителем холода Чысхааном. <..> Фестиваль пройдет с 21 по 25 марта", - отметили в иеетре. Деталь 1, применяется метод цитирования.

Как пояснили ТАСС организаторы, ожидается участие иностранных туристов, в том числе из стран АТР. По их данным, за прошлый год Оймяконский район посетили около 1 тыс. туристов. Большинство из них - туристы из зарубежных стран - Китая, Франщии, Германии, Японии, Великобритании, США <... Деталь 2.

Полюс холода в Северном полушарии расположен, по одной из версий, в местности Томтор Оймяконского района Якутии. В феврале 1933 года там зарегистрировали температуру минус 67,7 градусов. Среднемесячная температура января составляет минус 61 градусов - при такой низкой температуре живут и работают люди» - Бэкграунд.

По предложенной нами классификации, современную новость можно разделить условно на три вида: короткую (в профессиональном жаргоне «инофрмашка»), развернутую новость (или информационная заметка), а также на так называемую «молнию». 
Таблица 1

Типы новостей в современных интернет-СМИ.

\begin{tabular}{|c|c|c|}
\hline Типы & Содержание & Структура \\
\hline $\begin{array}{c}\text { короткая } \\
\text { новость }\end{array}$ & $\begin{array}{l}\text { ответы на вопросы: Что?/Кто? Где? } \\
\text { Когда? }\end{array}$ & $\begin{array}{c}\text { насчитывает 10-20 строк. Состоит из ядра (что именно } \\
\text { произошло), 1-2 деталей, бэкграунда. }\end{array}$ \\
\hline $\begin{array}{c}\text { развернутая } \\
\text { новость }\end{array}$ & $\begin{array}{l}\text { ответы на вопросы: Что?/Кто? Где? } \\
\text { Когда? Почему? Каким образом? и т.П. }\end{array}$ & $\begin{array}{c}\text { насчитывает от } 4 \text { до } 10 \text { абзацев. } \\
\text { Состоит из ядра, 2-х и более деталей и развернутого } \\
\text { бэкграунда. }\end{array}$ \\
\hline молния & $\begin{array}{c}\text { ответы на вопросы: Что?/Кто? Где? } \\
\text { Когда? }\end{array}$ & $\begin{array}{c}\text { состоит из 1-2 строк, в которых сообщается что } \\
\text { произошло (подробности происшествия еще } \\
\text { неизвестны) }\end{array}$ \\
\hline
\end{tabular}

Что касается языка и стилистики современных новостей, то здесь не приветствуются сложные синтаксические конструкции (одно предложение - одна мысль), языковые средства выразительности, слова с многозначной семантикой, а также профессионализмы, архаизмы, историзмы, научная или деловая лексика. Оптимальная длина предложений 6-8 слов, отсутствие или сведение к минимуму причастных или деепричастных оборотов, вводных конструкций и других синтаксических оборотов, усложняющих текст. В заголовках нежелательно использовать инверсию и пассивный залог.

Требования к оперативности и стилистике в подобных материалах остались те же, но стали намного выше. Современному журналисту, работающему в новостных отделах интернет-СМИ, необходимо учитывать мультимедийные особенности данного жанра: любая новость должна соответствовать как минимум формуле «текст+ изображение» (фото). Современные новости также обязательно сопровождаются гиперссылками, перейдя на которые можно прочитать связанные с событием материалы.

В заключение нашего исследования отметим, что в современных интернет медиа мы наблюдаем процесс слияния традиционных информационных жанров в единый для большинства новостных агентств мультимедийный формат подачи информации. Мы определили его как жанр «новость», который перенял все основные содержательные аспекты у информационных газетных жанров (это и ответы на 6 основных вопросов, и принцип перевернутой пирамиды), но в то же время обрел более четкую структурную и композиционную форму.

\section{ЛИТЕРАТУРА}

1. Колесниченко А.В. Практическая журналистика - М.: МГУ, 2013. С. 17-18.

2. В Якутии организуют автомобильный тур на полюс холода для иностранных гостей. ТАСС, [Электронный ресурс] - URL: http://tass.ru/obschestvo/5028180 (дата обращения: 13.09.2021г.) 